\title{
Sorption properties of bread based on oatmeal
}

\author{
Tetiana Sylchuk, Vita Tsyrulnikova, \\ Vira Zuiko, Anastasiia Riznyk
}

National University of Food Technologies, Kyiv, Ukraine

Keywords:

Oatmeal

Bread

Sorption

Isotherms

\section{Article history:}

Received 01.07.2020

Received in revised

form 30.11.2020

Accepted 30.06.2021

\section{Corresponding author:}

Anastasiia Riznyk

E-mail:

riznyk_nastya2707@

ukr.net

\section{DOI:}

$10.24263 / 2304-$

974X-2021-10-2-12

\section{Abstract}

Introduction. For improving the quality of gluten-free bread, it is offered to use hydrocolloids. The aim of the study is to determine the sorption characteristics of bread from oat flour and optimize its storage conditions.

Materials and methods. To determine the sorption characteristics, an Autosort apparatus was used. To control humidity, the method of high performance liquid chromatography was used. The relative humidity conditions were varied from 0 to $90 \%$ at a temperature of $25^{\circ} \mathrm{C}$.

Results and discussion. The efficiency of joint use of glucanodelta-lactone and food casein for bread production with the use of oatmeal has been proved. The regularities of the influence of oatmeal on the properties of the dough and the qualitative characteristics of bread are determined. It was found that the introduction of glucanodelta-lactone in the amount of $1.0 \%$ by weight of oatmeal in the dough in combination with food casein causes an increase in the specific volume and porosity of the finished products. According to the results of determining the change in the specific volume of dough during fermentation, it was found that the increase in the quality of gluten-free bread with the introduction of glucan-delta-lactone and food casein is associated with increased gas-holding capacity of dough semi-finished products. The positive effect of the use of glucano-delta-lactone in the technology of rice bread on the elastic properties of the crumb of the products has been clarified. The identified patterns make it possible to predict the extension of the shelf life of finished products.

In the studied products, adsorption begins as polymolecular and ends with capillary condensation with developed hysteresis, in which the amount of absorbed moisture and removed does not match. The adsorption process is influenced by the shape and radius of the capillaries.

The introduction of oatmeal in combination with casein and glucandelta-lactone affected the redistribution of pores by radius, increasing the total volume of larger pores with a radius within $(50-55) \times 10^{-10} \mathrm{~m}$ almost twice, compared to the structure of the product exclusively on oatmeal.

Conclusions. Addition of oatmeal in the amount of $100 \%$ with glucan-delta-lactone in the amount of $1 \%$ and natural protein of animal origin - casein in the amount of 5\% improves bread quality: increases porosity, increased specific volume, which has a positive effect on the sorption properties of finished products. 


\section{Introduction}

It is considered that oats and oat products are not suitable for baking dough or bread, because it does not contain gluten, although not many studies have been conducted to study new applications. Differences in oat varieties regarding the potential for making gluten-free bread recipes based on a pancake-like system (known as dough) (Thompson, 2003). However, it is not known what factors are important for bread making and whether, for example, a high content of $\beta$-glucan will be suitable for bread procurement (Ronda et al., 2015). The same goes for the fat content, which is extremely high in oats compared to wheat. This high fat content in oats requires an additional processing step to avoid damaging the sensory quality of the grains (Hoffenberg et al., 2000).

The quality of most foods largely depends on their physical, chemical and microbiological stability. This stability is mainly due to the relationship between the equilibrium moisture content (EMC) of the food material and its corresponding water activity $\left(a_{w}\right)$ at a certain temperature (Demirkesen et el., 2010). The sorption isotherm describes the thermodynamic relationship between water activity and food moisture balance at constant temperature and pressure (Torbica et al., 2010). Knowledge and understanding of sorption isotherms are extremely important in food science and technology for the design and optimization of drying equipment, packaging design, quality prediction, stability, shelf life and for calculating moisture changes that may occur during storage (Wehrle et al., 1998). The sorption isotherm can be used to study the structural features of a food product, such as surface specific surface area, pore volume, pore size distribution, and crystallinity (Ramanathan, 1994). Sorption isotherms can be obtained by adsorption or desorption; the difference between these curves is defined as hysteresis (Ajisegiri et al., 2007).

The most common equations used to describe sorption in foods include the Langmuir equation, the Brunauer equation, the Emmett, Teller (BET) model, the Oswin model, the Smith model, the Helsey model, the Henderson model, the Iglesias Kirife equation, the GAB model, and the Peleg model et al. (Paderewski et al., 1999). Thus, the net isosteric heats of sorption for beta-glucan rich biscuits, calculated using Clausius-Clapeyron equation, showed an exponential relationship with moisture content (Adeseye et al., 2019). Based on the results of the study of sorption by scientists, it is confirmed that the quality of bread flour is significantly affected by storage conditions (Panjagari et al., 2014).

Knowledge and understanding of sorption isotherms are critical for equipment design, prediction of food quality, stability and shelf life, packaging design, and for calculating moisture changes that may occur during storage (Gray et al., 2003). The MSI of most foods are nonlinear, usually S-shaped, and are classified as type II isotherms (Paderewski et al., 1999). Several attempts have been made to describe sorption isotherms using mathematical models and to confirm the effectiveness of such models using statistical methods (Sciarini, 2017). It has been scientifically proven and established that the quality of products deteriorates due to changes in sensory properties, which is accompanied by an increase in the number of harmful microbes, and these deteriorating changes increase with increasing water activity. Water activity (aw) is the ratio of water vapor pressure over a given product to vapor pressure over pure water at the same temperature (Nascimento et al., 2013).

The aim of the study is to determine the sorption characteristics of bread from oat flour and optimize its storage conditions. It is studied the bread, prepared with the use of oatmeal enriched with biologically valuable prescription components - casein and glucan-deltalactone. 


\section{Materials and methods}

\section{Methods of sorption measurements}

To estimate the parameters of the porous structure of the materials used the method of static interval isothermal sorption. The weight version of the sorption method allows you to simultaneously measure the amount of steam absorbed by the sorbent and the equilibrium pressure of the same steam over the created system. The principle of the weight method of sorption study is to determine the amount of sorbed substance by the difference in weight of the sample of sorbent before and after sorption (Ramanathan et al., 1994).

To do this, we used a sorption unit (Figure 1), which consists of two main parts: a vacuum, which serves to create a residual air pressure of $10^{-3} \mathrm{~Pa}$, and a working one, in which sorption measurements performed directly. The working part $A$ is placed in an air thermostat equipped with a heater and a contact thermometer.

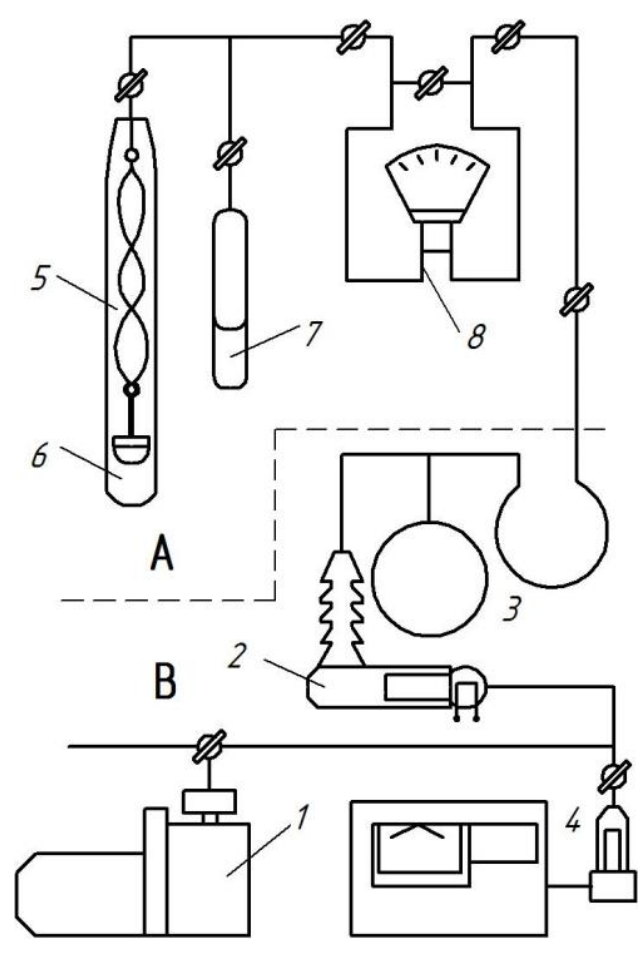

Figure 1. High-vacuum sorption installation scheme

The working part of the installation is a detachable cylindrical tank (5), to the head of which are suspended spiral scales of McBen. A thin-walled glass cup with a sample (6) is attached to the lower end of the spiral. Pre-calibrated quartz spirals should have a sensitivity of about $0,5 \times 10^{3} \mathrm{~m} / \mathrm{kg}$ and have no hysteresis. The ampule (7) contains a liquid whose vapors sorbed. Sorption experiments performed at a temperature of $298 \mathrm{~K}$. 


\section{— Food Technology —}

Prior to the determination, the test sorbent and sorbate subjected to vacuum at a residual pressure of $10^{-3} \mathrm{~Pa}$ to constant weight, in order to remove volatile substances.

The B-630 cathetometer used to supply steam, after which the stretching of the quartz spirals monitored and the kinetic curve of steam absorption by the sorbent constructed. Measurements performed with an accuracy of $5 \times 10^{-5} \mathrm{~m}$.

Experimental data were used to calculate the equilibrium number of grams of sorbed steam $(x / m)$ per gram of sorbent by the equation:

$$
\frac{x}{m}=\frac{\gamma \times \Delta n}{m}
$$

where $\Delta n$ - spiral elongation, $\mathrm{mm} ; m$ - the amount of polymer, $\mathrm{g} ; \gamma-$ the price of spiral division, $\mathrm{g} / \mathrm{mm}$, and to calculate the amount of adsorption $a$ (mmol) per $1 \mathrm{~g}$ of sorbent:

$$
a=\frac{x \times 1000}{M \times m},
$$

After equilibrating, the equilibrium pressure of the sorbate vapor is measured. The obtained data was presented in the form of a sorption isotherm, which was constructed in the coordinates $x / m(a)$ depending on the relative vapor pressure $p / p_{s}$, where $p_{s}$ is the saturated vapor pressure of the sorbate at the study temperature.

The Autodesk system used to determine the sorption characteristics. The method of high performance liquid chromatography used to control the humidity. Relative humidity conditions ranged from 0 to $90 \%$ at a temperature of $25^{\circ} \mathrm{C}(9)$.

Sorption characteristics systematize data on equilibrium and monomolecular moisture levels, based on which it is possible to correctly determine the methods for processing, storage, and packaging of finished products (Ramanathan et al., 1994).

The relationship between the equilibrium humidity $M$ and the activity of water aw was determined experimentally and the results depending on the temperature built sorption isotherms (Ajisegiri et al., 2007).

\section{Calculation of the specific surface area $S_{\mathrm{s}}$}

Adsorption isotherms make it possible to determine the capacity of a monolayer of a test sample, which can be used to calculate its specific surface area $S_{s}$. The capacity of a monolayer is the amount of adsorbate that can be accommodated in a fully filled adsorption layer 1 molecule thick - a monolayer - on the surface of a unit mass $(1 \mathrm{~g})$ of a solid. From the capacity of a monolayer $a_{m}$, expressed in moles of adsorbate per gram of adsorbent, the specific surface area as the surface area of $1 \mathrm{~g}$ of a solid $S_{s}$ is calculated by the simple equation:

$$
S_{s}=a_{m} \cdot \omega \cdot N_{A},
$$

where $\omega$ is the average area occupied by an adsorbate molecule in a filled monolayer, $N_{A}$ is Avogadro's number.

The value of $a_{m}$ was determined using the equation of the sorption isotherm obtained by Brunauer, Emmett and Teller (BET equation) (Paderewski et al., 1999),

$$
a=\frac{a_{m} \cdot c \cdot p / p_{S}}{\left(1-p / p_{S}\right) \cdot\left[1+(c-1) \cdot p / p_{S}\right]},
$$

where $a$ - the equilibrium number of moles of sorbed substance per gram of sorbent, $p / p s-$ relative vapor pressure, $c-$ a constant.

To calculate the value of $a_{m}$, the BET equation modified: 


$$
\begin{aligned}
& \text { - Food Technology- } \\
& \frac{p / p_{S}}{a \cdot\left(1-p / p_{S}\right)}=\frac{1}{a_{m} \cdot c}+\frac{c-1}{a_{m} \cdot c} \cdot p / p_{S},
\end{aligned}
$$

Equation type 4 is derived for sorbents, in the pores of which the sorption process accompanied by the phenomenon of capillary condensation. For such sorbents, the sorption isotherm has a typical S-shape with sorption hysteresis. Similarly, this equation formally is used to calculate the values $S_{s}$ of non-porous adsorbents.

The calculation $S_{s}$ was performed on the basis of experimental data, constructing the sorption isotherm in coordinates $a=\int\left(p / p_{S}\right)$.

\section{Calculation of the total pore volume $W_{0}$}

Depending on the nature of the porous structure of the sorbent, there are different methods of calculating $W_{0}$. In our case, the total pore volume calculated from the maximum amount of sorbed substance, because the sample belongs to the group of mesoporous sorbents characterized by $\mathrm{S}$-shaped sorption isotherms. equation:

The absorption of the sorbed substance $a_{\max }$ occurs at $p / p_{s}=1$, according to the

$$
W_{0}=a_{\max } \cdot V_{\max },
$$

The right-hand side of this equation is the maximum volume of sorbed matter, which is essentially equal to the volume of pores available to the molecules of this sorbate.

\section{Results and discussion}

Effect of glucan-delta-lactone (GDL) on the change of technological characteristics and quality of bread

The study of the effect of glucan-delta-lactone on the change of technological characteristics and quality of bread depending on its dosage is presented in Table 1.

\begin{tabular}{|c|c|c|c|c|}
\hline \multirow[t]{2}{*}{ Quality indicators } & \multirow{2}{*}{$\begin{array}{l}\text { Control } \\
\text { sample }\end{array}$} & \multicolumn{3}{|c|}{ Sample with the addition of GDL, \% } \\
\hline & & $\mathbf{0 , 5}$ & $\mathbf{1 , 0}$ & 1,5 \\
\hline \multicolumn{5}{|c|}{ Semi-finished dough } \\
\hline Titrated acidity & 2,7 & 2,7 & 2,8 & 2,8 \\
\hline Active acidity & 4,3 & 4,4 & 4,4 & 4,5 \\
\hline $\begin{array}{l}\text { Gas formation, } \mathrm{cm}^{3} / 100 \mathrm{~g} \text { of } \\
\text { dough }\end{array}$ & 420 & 408 & 400 & 398 \\
\hline Specific volume, $\mathrm{cm}^{3} / \mathrm{g}$ & 1,60 & 2,3 & 2,4 & 2,1 \\
\hline \multicolumn{5}{|c|}{ Bread } \\
\hline Specific volume, $\mathrm{cm}^{3} / \mathrm{g}$ & 1,86 & 2,55 & 2,70 & 2,18 \\
\hline Acidity, deg & 3,1 & 3,1 & 3,1 & 3,2 \\
\hline Porosity, $\%$ & 52,3 & 68,1 & 69,7 & 66,4 \\
\hline
\end{tabular}

Influence of GDL on dough properties and bread quality

Table 1 
The data obtained indicate that during fermentation of the dough from glucano-deltalactone there is a slight decrease in the intensity of acid accumulation, which is apparently associated with a decrease in the activity of lactic acid bacteria and yeast Saccharomyces during maturation of dough semi-finished products.

Thus, the introduction of glucano-delta-lactone in the amount of $0,5-1,5 \%$ by weight of flour leads to a decrease in the amount of carbon dioxide released by $1,9-3,8 \%$ relative to the control. Obviously, a colloidal solution of cellulose ether wraps a thin film of yeast cells, limiting access to nutrients. The study of quality indicators of finished products showed that their specific volume in the case of application of glucan-delta-lactone in the amount of $0,5 \%$ and $1,0 \%$ by weight of flour increases by 35,0 and $37.1 \%$, respectively, compared with the control. The porosity of the crumb is improved by 30,0 and $32,5 \%$ relative to the control sample. The obtained results are explained by the improvement of the gas holding capacity of the dough, as a result of which, despite the reduction of gas formation in the semi-finished product, the losses of carbon dioxide formed during fermentation are insignificant.

As a result of experimental researches it is established that increase in dosage of GDL above $1.0 \%$ to weight of flour is inefficient as at the same time the crumb of products is condensed, has worse developed porosity, bread has smaller specific volume, and on its surface there are cracks.

The increase in the specific volume of the dough with the combined application of glucano-delta-lactone and casein is more intense compared to the control sample without hydrocolloid. This is due to the high water holding capacity of GDL, which reduces the content of free moisture in the system, that is, the layers of intermicellar fluid between the colloids of the dough are reduced, which leads to the formation of a homogeneous framework of the semi-finished product, resulting in improved structural and mechanical properties.

The results of the research became the basis for further determinations of the sorption properties of finished bread products.

\section{Optimization of the prescription composition of oatmeal bread}

The study of the chemical composition of alternative raw materials - oatmeal, allows understanding and explain the main processes of dough formation, and most importantly to choose the winning combinations of improvers in order to eliminate possible shortcomings (Paderewski et al., 1999).

Given the fact that oat products do not contain gluten (Thompson et al., 2003), thus questioning the use of oats as a main component in baking, an effective measure to mimic the gluten skeleton in the technology of gluten-free bakery products based on oatmeal is the use of various improvements.

Our results are promising, because even without process optimization and without understanding the functionality of all oat components except beta-glucans, the overall appearance of bread products and their specific volume lead us to think that there is room for much greater improvement. Our oat bread is similar to the bread that consumers are familiar with (Figure 2). We believe that the lack of knowledge is the main reason for the limited availability of oat bread. Oats, as an agricultural crop and as a raw material for the food industry, has features that must first be understood in order to be able to deal with them in the process of product development.

Nutritionists have confirmed that it is advisable to use glucan-delta-lactone (GDL) as a structurant of food systems ( $\mathrm{Li}$ et al., 2016). 

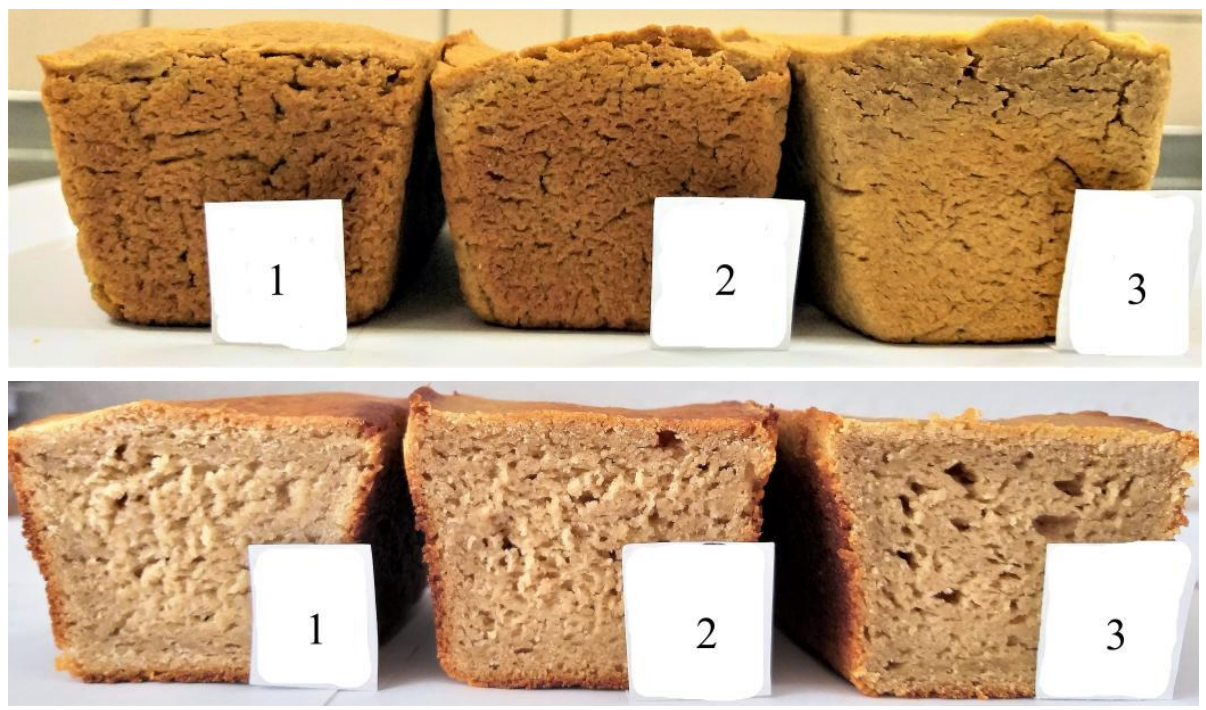

Figure 2. Picture of test baking results

1 - bread with $100 \%$ oatmeal; 2 - bread with $100 \%$ oatmeal and $1 \%$ GDL;

3 - bread with $100 \%$ oatmeal, $5 \%$ casein and $1 \%$ GDL

In the course of trial laboratory baking, it was found that the addition of only gdl in the technology of production of bread products is not sufficient. This technology needs the improvement.

To improve the viscoplastic properties of oat raw materials, we have selected a combination of a structuring agent and a protein-containing component of animal origin, taking into account the research of specialists in this field (Deora et al., 2014; Stathopoulos et al., 2008; Ziobro et al., 2016).

The next stage of our research was to conduct a trial baking of bread with the introduction of GDL and casein at the established optimal ratio.

During the study it was found that the introduction of oatmeal in the amount of $100 \%$ with a structuring substance (glucan-delta-lactone) in the amount of $1 \%$ and natural animal protein (casein) in the amount of 5\% improves the quality of bread: increases porosity, increases specific volume. The humidity and acidity of all baked samples remain within the norm set by the standard. This is because the introduction of oatmeal into the dough intensifies the fermentation process due to sugar, vitamins, minerals, which are an additional source of nutrition for yeast.

According to the results of the study, it was found that the best quality indicators are bread with a complete replacement of wheat flour with the addition of a structural component and protein of animal origin.

\section{Effect of temperature and relative humidity on equilibrium moisture content}

The next step was to study the sorption characteristics of the obtained samples.

The experimentally obtained values of equilibrium humidity $M, \%$ dry weight, and standard deviation $s_{d}$ of the investigated product at different values of water activity $a_{w}$ and 
at a temperature of $25^{\circ} \mathrm{C}$ for adsorption and desorption processes is shown in Table 2 . The equilibrium moisture content at each $\mathrm{a}_{\mathrm{w}}$ represents the mean value of three replications (Adeseye et al., 2019).

\section{Comparative characteristics of research results}

Table 2

\begin{tabular}{|c|c|c|}
\hline $\boldsymbol{a}_{\boldsymbol{w}}$ & $\boldsymbol{M}$ & $\boldsymbol{S}_{\boldsymbol{d}}$ \\
\hline 0,106 & 3,24959 & 0,0881 \\
\hline 0,249 & 5,46128 & 0,0787 \\
\hline 0,348 & 6,88063 & 0,1304 \\
\hline 0,443 & 8,39007 & 0,2291 \\
\hline 0,538 & 10,0220 & 0,2342 \\
\hline 0,629 & 12,0427 & 0,2482 \\
\hline 0,737 & 15,6526 & 0,3046 \\
\hline 0,818 & 19,9702 & 0,240 \\
\hline
\end{tabular}

Based on the obtained data, it is confirmed that the equilibrium moisture content increases with increasing in temperature at constant relative humidity and increases with increasing in relative humidity at constant temperature.

To compare sorption and desorption, the figures show the isotherms of all the studied samples (Figures 3, 4).

The sorption-desorption isotherms of water (Figures 3,4) are given in the coordinates: the amount of adsorbed water $(a)$ - its activity $\left(a_{w}\right)$, which is directly related to the relative equilibrium vapor pressure $\left(a_{w}=P / R_{S}\right)$.

To compare sorption and desorption are given isotherms in Figures 3: a sample of bread based on oatmeal with the addition of 1\% GDL (Figure 3, a), a sample of bread based on oatmeal from a combination of $1 \%$ GDL and 5\% casein (Figure 3, b) and a sample of bread based on oatmeal without additives (Figure 3, c).

Analysis of isotherms showed that the characteristic S-shaped configuration of the lines corresponds to polymolecular adsorption. In the works (Adeseye et al., 2019; Panjagari et al., 2014; Gray et al., 2003) note that in the adsorption accompanied by capillary condensation, hysteresis is often observed, so we can conclude that in the studied products adsorption begins as polymolecular and ends with capillary condensation with developed hysteresis, in which the amount of absorbed moisture and coincides.

It is known (Gomez et al., 2013) that the hygroscopicity of raw materials depends on its porosity. It is obvious that the main part of moisture in the investigated raw material condenses in small pores of the adsorbent - capillary condensation. To test this hypothesis, the distribution of pore volume by radius is analyzed (Figure 3 ) and the pore volume $(V)$ in the studied raw material is determined (Paderewski et al., 1999):

$$
V=\int_{a}^{b} f(R) d R,
$$

The results of calculations of pore volume with a certain radius for the studied bread samples are shown in Table 3. 

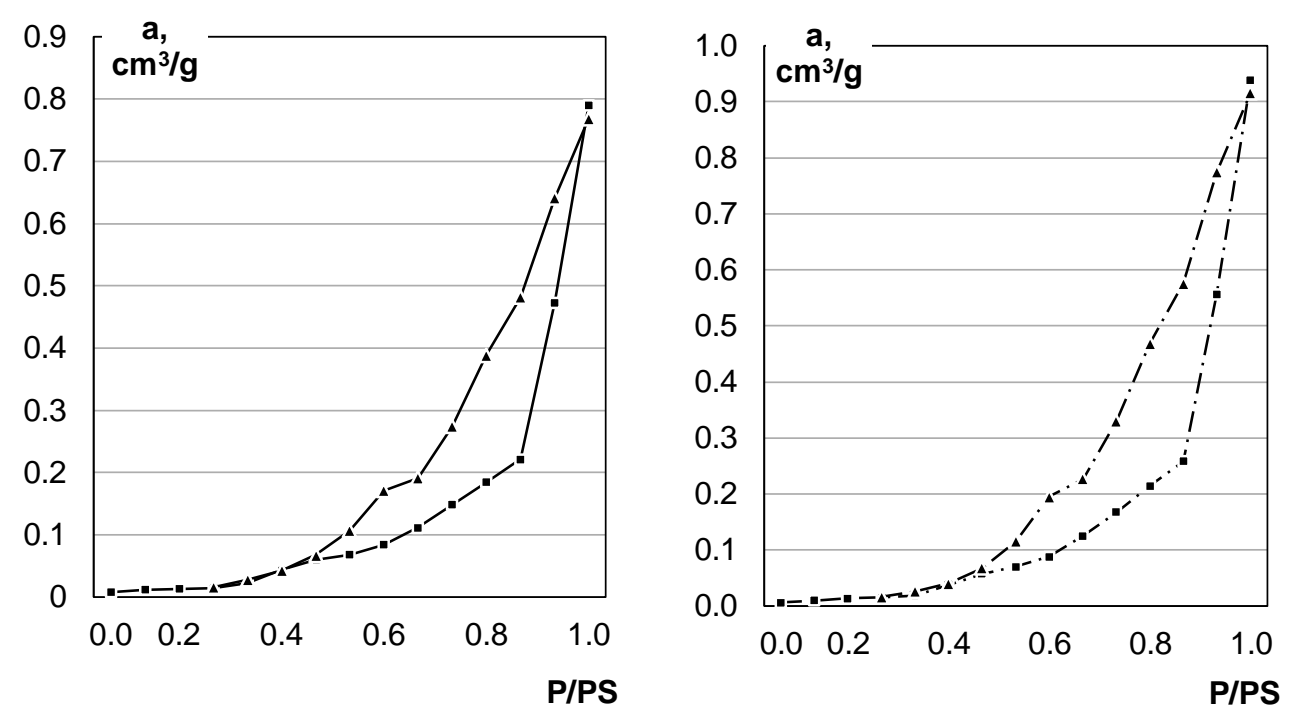

a

b

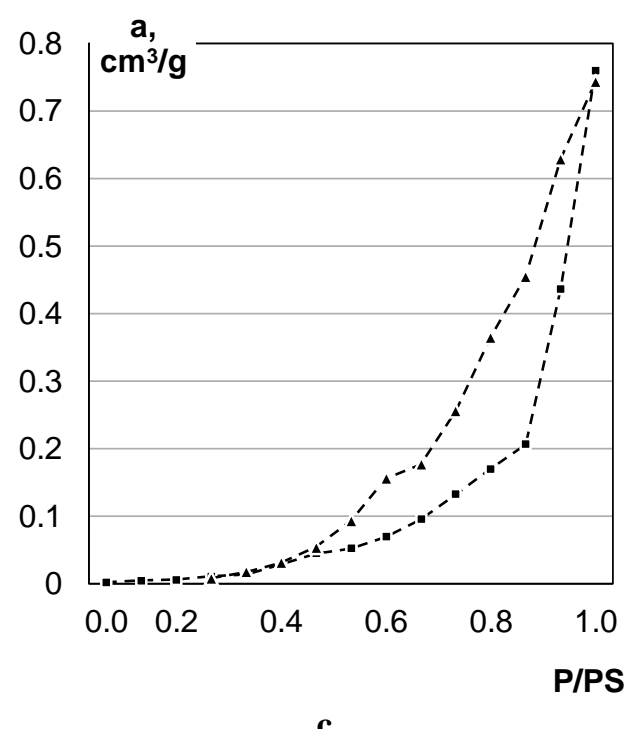

Figure 3. Sorption isotherms of adsorption and desorption processes a - bread with $100 \%$ oatmeal and $1 \%$ GDL;

$\mathrm{b}-$ bread with $100 \%$ oatmeal, $5 \%$ casein and $1 \%$ GDL; c-bread with $100 \%$ oatmeal. 


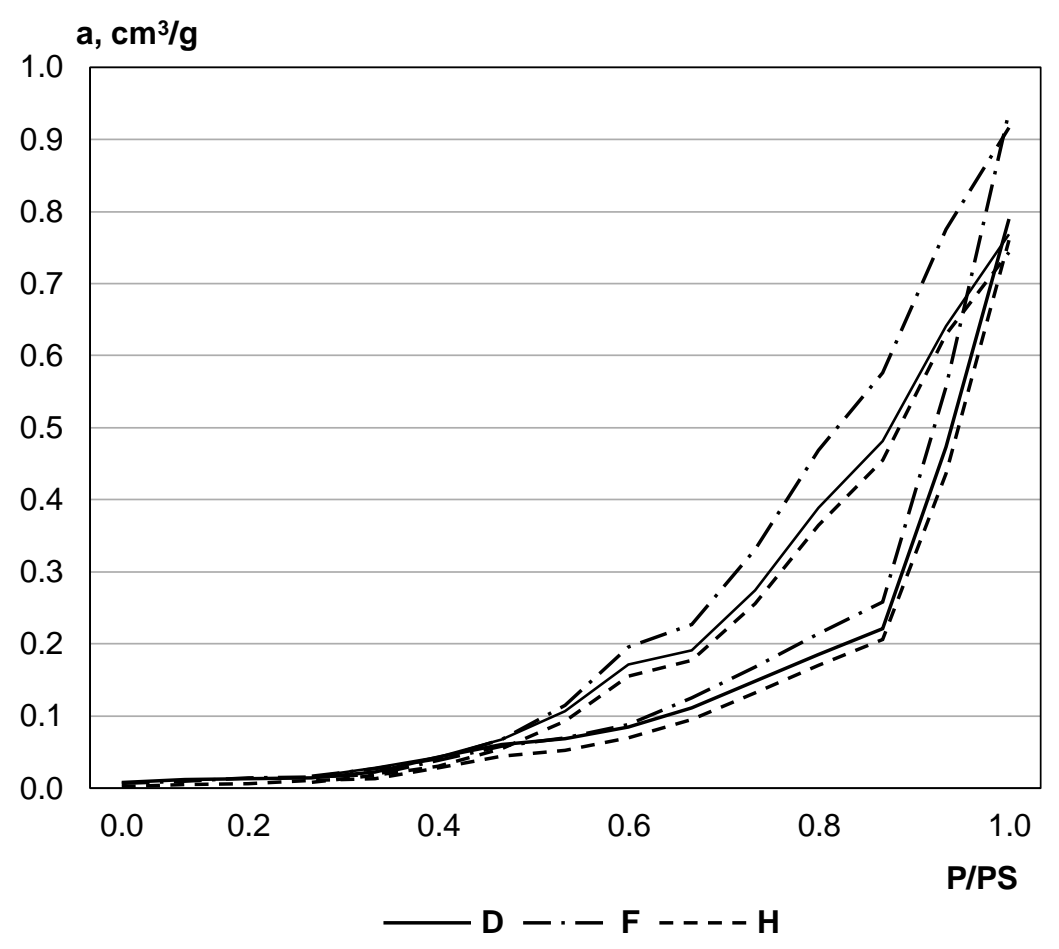

Figure 4. Sorption isotherms of adsorption and desorption processes.

Generalized results for the three studied samples:

D - bread with $100 \%$ oatmeal and $1 \%$ GDL;

$\mathrm{F}$ - bread with $100 \%$ oatmeal, $5 \%$ casein and $1 \%$ GDL;

$\mathrm{H}$ - bread with $100 \%$ oatmeal.

Structural characteristics of samples

Table 3

\begin{tabular}{|l|l|c|c|c|c|}
\hline № & \multicolumn{1}{|c|}{ Sample name } & $\mathbf{S}, \mathbf{~ m}^{\mathbf{2}} / \mathbf{g}$ & $\mathbf{R}^{\mathbf{2}}$ & $\mathbf{V s ~} \mathbf{s}_{\mathbf{c}} / \mathbf{g}$ & $\mathbf{D}, \mathbf{A}$ \\
\hline 1. & 100\% oatmeal, 1\% GDL & 54 & 0,8619 & 0,79 & 585 \\
\hline 2. & 100\% oatmeal, 5\% casein, 1\% GDL & 53 & 0,9788 & 0,94 & 696 \\
\hline 3. & 100\% oatmeal & 56 & 0,4964 & 0,76 & 543 \\
\hline
\end{tabular}

Based on the first graph of moisture adsorption, we can say that the samples adsorbed moisture to a pressure of $P / P_{s}=0,3$ is not active, because there was a so-called adsorption of the surface layer of samples, and then - penetration into the internal volume, and they were activated. After all, under the pressure of moisture, the samples loosened and absorbed vapors, because the pore volume of the samples is quite high.

The sample with the type " $100 \%$ oatmeal, $5 \%$ casein, $1 \%$ improver" gained the most moisture (Figure 5, b), the pore volume was equal to: $V_{s}=0,94 \mathrm{~cm}^{3} / \mathrm{g}$, and the sample with the type "100\%" gained the least moisture. Oatmeal (Figure 5, c), as evidenced by its pore volume: $V_{s}=0,76 \mathrm{~cm}^{3} / \mathrm{g}$ (from the Table of structural characteristics). 
DV/DR

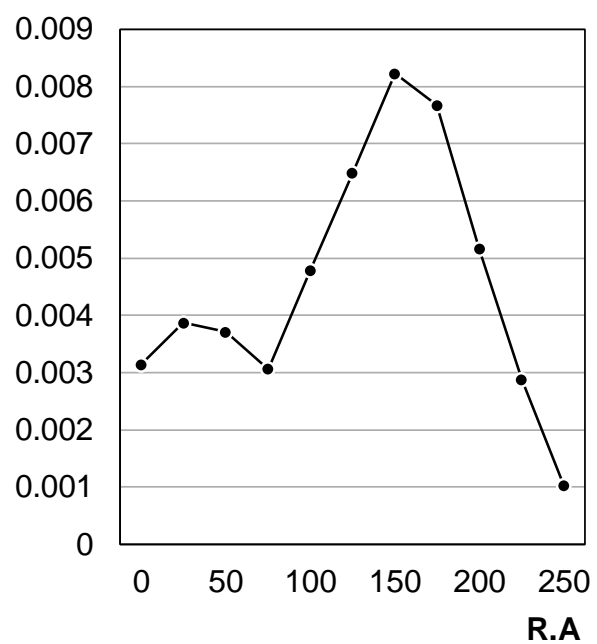

DV/DR

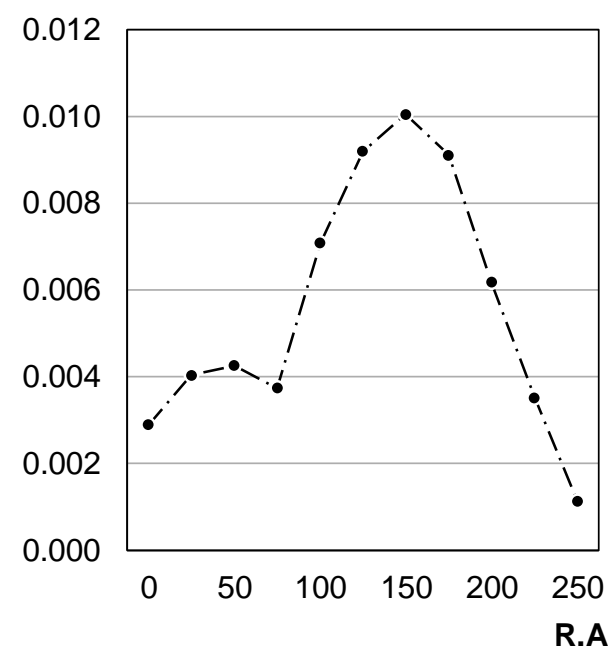

a

b

DV/DR

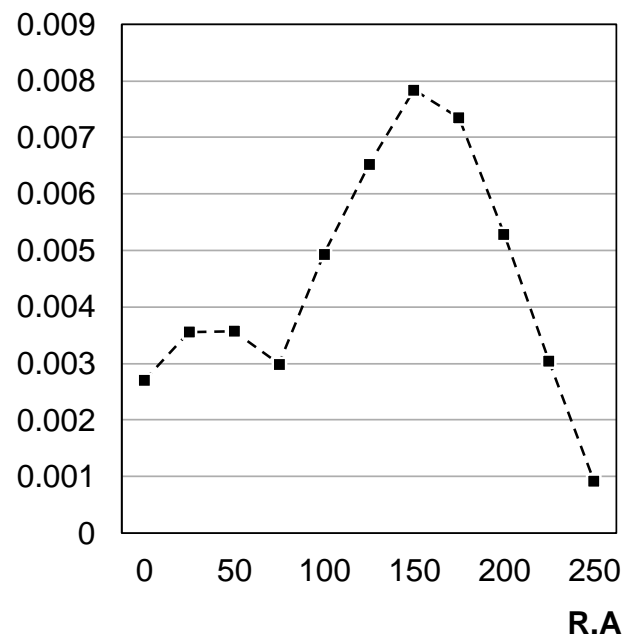

c

Figure 5. Distribution of pore volume by their radius in the raw material: a - bread with $100 \%$ oatmeal and $1 \%$ GDL $\mathrm{b}$ - bread with $100 \%$ oatmeal, $5 \%$ casein and $1 \%$ GDL c - bread with $100 \%$ oatmeal 


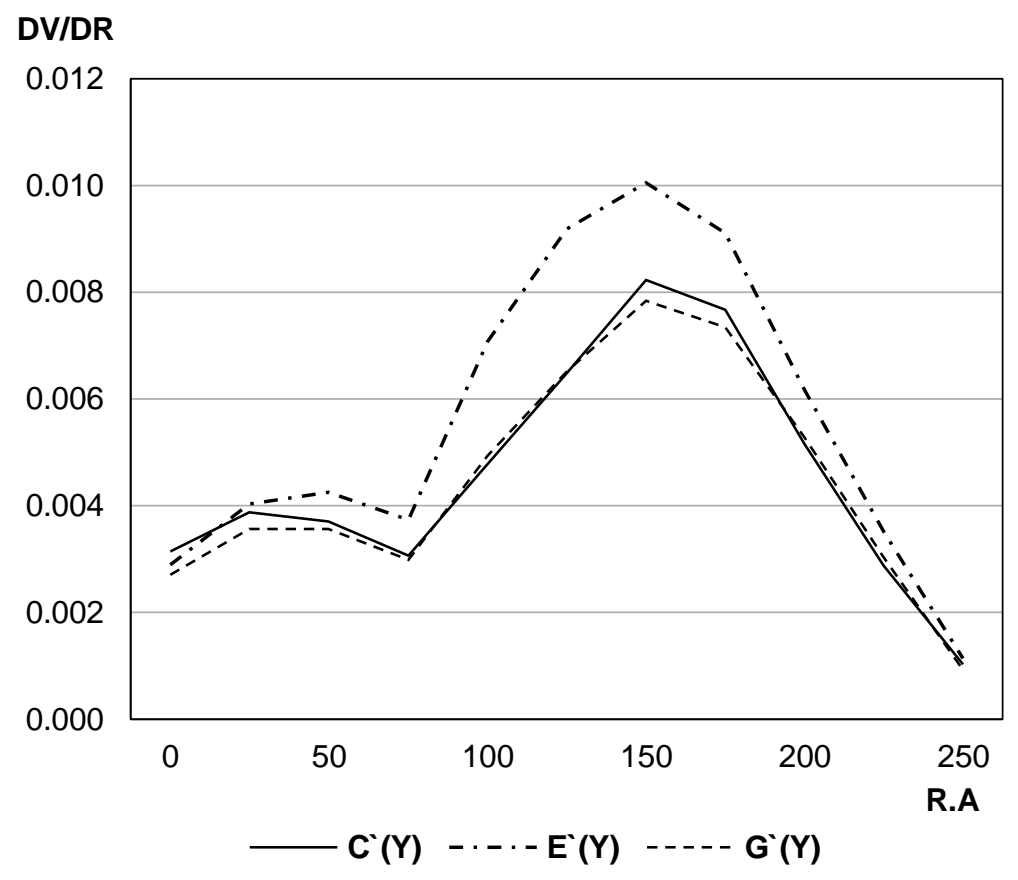

Figure 6. Distribution of pore volume by their radius in the raw material. Generalized results for the three studied samples:

C' - bread with $100 \%$ oatmeal and $1 \%$ GDL;

E' - bread with $100 \%$ oatmeal, $5 \%$ casein and $1 \%$ GDL;

$\mathrm{G}^{\circ}$ - bread with $100 \%$ oatmeal

From the data in Figures 5, 6 and Table 2 we can conclude that the addition of a composition with $1 \%$ GDL and 5\% casein to the recipe of oatmeal bread affected the redistribution of pores by radius, increasing the total volume of larger pores with a radius within $(50-55) \times 10^{-10} \mathrm{~m}$ compared to other samples.

The hysteresis loops (the area between the adsorption curve going from zero to the top and the desorption going from top to zero) in the samples are almost the same in shape, indicating similar structural data.

The radius distribution curve shows that the sample type " $100 \%$ oatmeal, $5 \%$ casein, $1 \%$ improver" has the highest peak, is it has the largest large pores with a diameter of 64,8 angstroms. The smallest peak in a sample of the type " $100 \%$ oatmeal", it has few large pores, so it has the smallest pore volume.

All samples have almost a similar adsorption structure, because their adsorption curves coincide in shape. Although in the sample type " $100 \%$ oatmeal, $5 \%$ casein, $1 \%$ improver" the curve is the largest in the volume of the hysteresis loop, and in the sample type " $100 \%$ oatmeal" - the smallest.

From the graph of pore distribution by radii you can see clearly and calculate the number of pores. This is defined as follows: the perpendicular lowered from the end of the rounding to the abscissa on each side and the area under the perpendiculars gives the number of pores. 
All samples have excellent convex hysteresis, but then the desorption line does not fall on the adsorption line completely and does not end at zero, because the samples have chemisorption, which determines their residual removal of sorbate.

\section{Conclusions}

1. For all studied samples there was a significant effect of temperature on the equilibrium sorption of moisture in the range of studied temperatures.

2. Sorption isotherms of the tested bread samples had an S-shape, this type is inherent in food systems.

3. Research and analysis of sorption properties confirmed our theory of improving the viscoplastic characteristics of oatmeal in bread production technology by including glucan-delta-lactone $(1 \%)$ and casein $(5 \%)$ in the prescription components.

4. The analysis of obtained results to determine the effect of the studied raw material on the change in the specific volume of oatmeal during fermentation shows that the joint application of casein and glucano-delta-lactone has a synergistic effect on the gas holding capacity of dough semi-finished products high-volume yield.

\section{References}

Adeseye R., Ndigwe V., John A.V., (2019), Moisture sorption isotherm study on breadfruit (artocarpus altilis) flour, Department of Food Science and Technology, Federal University of Technology, 20(4).

Ajisegiri, E. S. A., Chukwu O., Sopade P. A., (2007), Moisture-sorption study of locally parboiled rice, $A u$ J. T., 11 (2), pp. 86-90.

Demirkesen I., Mert B., Sumnu G., Sahin S., (2010), Rheological properties of glutenfree bread formulations, Journal of Food Engineering, 96(2), pp. 295- 303.

Deora Na. S., Deswal A., Mishra H. N., (2014), Functionality of alternative protein in gluten-free product development, Food Science and Technology International, 21(5), pp. 786-800.

Gomez M., Talegon M., Hera E. dela, (2013), Influence of mixing on quality of glutenfree bread, Journal of Food Quality, 36, pp.139-145.

Gray J. A., Bemiller J. N., (2003), Bread staling: Molecular basis and control, Comprehensive Reviews in Food Science and Food Safety, 2, pp. 1-21.

Hoffenberg E.J., Haas J., Drescher A., Barnhurst R., Osberg I., Bao F., Eisenbarth G., (2000), Atrial of oats in children with newly diagnosed celiac disease, J. Pediatr, 137, pp. 361-366.

Kutsova A. E., Kutsov S. V., Serhiienko I. V., Liutykova A. O., (2015), Vykorystannia vivsianoho tolokna $\mathrm{v}$ tekhnolohii produktiv funktsionalnoho pryznachennia, Visnyk MAKh, 2, pp. 23-27.

Li J. M., Nie S. P., (2016), The functional and nutritional aspects of hydrocolloids in foods, Food Hydrocolloids, 53, pp. 46-61.

Mancebo C. M., Miguel M. A. S., Martinez M. M., Gomez M., (2015), Optimisation of rheological properties of gluten-free doughs with HPMC, psyllium and different levels of water, Journal of Cereal Science, 61, pp. 8-15. 
Nascimento A., Fiates G., Anjos A., Teixeira E., (2013), Analysis of ingredient lists of commercially available gluten-free and gluten-containing food products using the text mining technique, Int. J. Food Sci. Nutr., 64 (2), pp. 217-222.

Paderewski M., (1999), Adsorption processes in chemical engineering. WNT, Warsawa.

Panjagari N.R., Singh A.K., Ganguly S., Indumati K.R., (2014), Beta-glucan rich composite flour biscuits: modelling of moisture sorption isotherms and determination of sorption heat, Dairy Technology Division, National Dairy Research Institute, Association of Food Scientists \& Technologists (India).

Ramanathan S., Cenkwoski S., (1994), Sorption isotherm of flour and flow behaviour of flour as influenced by flow compaction, Department of Agricultural Engineering. University of Winnipeg, Manitoba, MB, Canada.

Ronda F., Perez-Quirce S., Lazaridou A., Biliaderis C. G., (2015), Effect of barley and oat b-glucan concentrates on gluten-free rice based doughs and bread characteristics, Food Hydrocolloid, 48, pp. 197-207.

Sciarini L. S., Bustos M. C., Vignola M. B., Paesani C., Salinas C. N., Perez G. T., (2017), A study on fibre addition to gluten free bread: its effects on bread quality and in vitro digestibility, J. Food Sci. Technol., 54(1), pp. 244-252.

Stathopoulos C. E., O’Kennedy B. T., (2008), A rheological evaluation of concentrated casein systems as replacement for gluten: Calcium effects, International Journal of Dairy Technology, 61, pp. 397-402.

Thompson T., (2003), Oats and gluten-free diet, J. Am. Diet. Assoc, 103, pp. 376-379.

Torbica A., Hadnađev M., Dapcevic T., (2010), Rheological, textural and sensory properties of gluten-free bread formulations based on rice and buckwheat flour, Food Hydrocolloids, 24, issues 6-7, pp. 626-632.

Wehrle K., Arendt E. K., (1998), Rheological changes in wheat sourdough during controlled and spontaneous fermentation, Cereal Chemistry, 75, pp. 882-886.

Ziobro R., Juszczak L., Witczak M., Korus J., (2016), Non-gluten proteins as structure forming agents in gluten free bread, J. Food Sci. Technol., 53(1), pp.571-580. 